\title{
Special issue WGP: "System-integrated intelligence: new challenges for product and production engineering"
}

\author{
Berend Denkena · Jürgen Gausemeier • \\ Bernd Scholz-Reiter
}

Published online: 17 November 2012

(C) German Academic Society for Production Engineering (WGP) 2012

This special issue contains selected contributions from the 1st Joint Symposium on System-integrated Intelligence: New Challenges for Product and Production Engineering (SysInt 2012), which took place from June 27th to 29th 2012 at the Hannover Centre for Production Technology $(\mathrm{PZH})$ at the Leibniz Universität Hannover.

The symposium provided a novel forum for both academia and industrialists to disseminate their latest innovations and practises. It was set up as a platform to exchange new developments, trends and upcoming ideas related to a great diversity of topics. Each contribution covers a different promising research area in the scope of system-integrated intelligence: Sensor technologies, sensorial materials, self-optimizing systems and self-controlled processes in production or logistic applications. Thereby, the main focus of all contributions was on the integration of new functions and mechanisms into components, parts and products as well as complete production and logistic systems.

This great diversity of topics was the result of the close cooperation of three outstanding German Collaborative Research Centres (CRC). This first symposium was hosted by the CRC 653 "Gentelligent Components in Their Lifecycle-Utilization of Inheritable Component Information in Product Engineering" from Leibniz Universität Hannover. The symposium was further co-organised by the CRC 614 "Self-optimizing Concepts and Structures in Mechanical Engineering", University of Paderborn and the Bremen CRC 637 "Autonomous Cooperating Logistic Processes-A Paradigm Shift and its Limitations". Further special sessions were focussed on the enabling technologies for sensorial materials and the recent advances in mechatronics and engineering technology by the "Integrated Solutions in Sensorial Structure Engineering" (ISIS) in Bremen, Germany, the University Teknologi Mara Selangor, Malaysia and the Project Group Mechatronic Systems Design, Fraunhofer Institute for Production Technology, Paderborn, Germany.

Within this Special Issue, the selection of contribution provides a great overview about the recent developments and provides an insight into new approaches and technologies in the area of system-integrated intelligence. It depicts promising advances in product and production engineering and will enhance future products and production systems with further abilities to learn or to optimize their behaviour during operation and to adapt to changing situations.

\footnotetext{
B. Denkena $(\bowtie)$

Garbsen, Germany

e-mail: Denkena@ifw.uni-hannover.de

J. Gausemeier

Paderborn, Germany

B. Scholz-Reiter

Bremen, Germany
} 